\title{
Forecasting (2018-2030) and the Demand of Hospital Pharmacy Technician Workforce at Over Twelve Years (2006-2017) in Saudi Arabia
}

\author{
Yousef Ahmed Alomi* $\mathbb{D}$, The \\ Former General Manager of General \\ Administration of Pharmaceutical Care, The \\ Former Head, National Clinical pharmacy and \\ pharmacy practice, The Former Head, Phar- \\ macy R\&D Administration, Ministry of Health, \\ Riyadh, SAUDI ARABIA.
}

Saeed Jamaan Alghamdi, General Administration of Pharmaceutical Care, Ministry of Health, Riyadh, SAUDI ARABIA.

Radi Abdullah Alattyh, General

Administration of Pharmaceutical Care, Ministry of Health, Riyadh, SAUDI ARABIA.

\section{Correspondence:}

Dr. Yousef Ahmed Alomi, The Former General Manager of General Administration of Pharmaceutical Care, The Former Head, National Clinical pharmacy and pharmacy practice, The Former Head, Pharmacy R and D Administration, Ministry of Health, Riyadh, SAUDI ARABIA

\section{Phone no: +966 504417712}

E-mail:yalomi@gmail.com

\section{Received: 06-03-2019;}

Accepted: 16-04-2019

Copyright: $\odot$ the author(s), publisher and licensee International Journal of Pharmacology and Clinical Sciences. This is an open-access article distributed under the terms of the Creative Commons Attribution Non-Commercial License, which permits unrestricted non-commercial use, distribution, and reproduction in any medium, provided the original work is properly cited.

This is an open access article distributed under the terms of the Creative Commons Attribution-NonCommercial-ShareAlike 4.0 License

Access this article online

\begin{tabular}{|c|c|}
\hline & www.ijpcs.net \\
\hline & \\
\hline
\end{tabular}

\begin{abstract}
Objectives: The workforce of hospital pharmacy technician is one the elements of pharmacy strategic plan in Saudi Arabia.: The purpose of this study is to explore the demand workforce of pharmacy technician at $\mathrm{MOH}$ hospitals over the past twelve years (2006-2017) and forecasting during (2018-2030) in the kingdom of Saudi Arabia. Methods: It is a retrospective analysis of twelve years (2006-2017) of Ministry of Health pharmacy technician workforce demand and forecasting in the future (20182030) at $\mathrm{MOH}$ organization practice. All data were derived from the Ministry of Health Statistical Year Books and any missing appropriate information about pharmacy technician workforce that will be estimated through allied healthcare professional's data in each region including gender or nationality. It included pharmacy technician and exclude all types of pharmacists or clinical pharmacist's workforce at $\mathrm{MOH}$ hospital setting. All calculations were based on $\mathrm{MOH}$ workforce standards of hospital with update literatures. All calculation was done used Microsoft Excel version ten. Results: The number of pharmacy technician demand based on optimum pharmacy and pharmacist. The pharmacy technician ratio $(1: 4)$ demand was $(21,212.6-26,091)$ with an average $(22,934.68)$. While with a ratio of $(1: 2)$ the number of pharmacy technician demand was $(7,410-8,859)$ with an average $(8,320.55)$. The number of pharmacy technician forecasting of a ratio $(1: 3)$ was $(14,300-17,475)$ with an average $(15,627.62)$. The forecasting number of pharmacy technician in the future within years (2018-2030) over thirteen years based on optimum pharmacy and pharmacist. The pharmacy technician ratio $(1: 4)$ forecast was $(33,898.6-45,803)$ with an average $(39,577.00)$. While with a ratio of (1:2) the number of the forecasting pharmacy technician was $(16,303-22,028)$ with an average $(19,034.31)$. The number of pharmacy technician forecasting of ratio $(1: 3)$ was $(25,100-33,916)$ with an average $(29,305.54)$. Conclusion: The demand of pharmacy technicians and forecasting in the future were determined. The ratio of pharmacist to pharmacy technician in the hospital practice should be standardized. An annual study on hospital pharmacy technician workforce is recommended in Saudi Arabia.

Keywords: Demand, Forecasting, Hospital, Pharmacy technician, Workforces, Ministry of Health, Saudi Arabia
\end{abstract}

\section{INTRODUCTION}

There are two types of pharmacy staff. The pharmacist included clinical pharmacist and advanced specialized clinical pharmacist. The other type calls supportive personal of pharmacy or pharmacy technician. Each type had specific functions and roles in the healthcare system. ${ }^{[1-3]}$ The workforce standard of each type should be with the balance to provide very cost-effective services to patients. Several State boards of pharmacy in America released different ratio of pharmacist to pharmacy technician starting from 1:2 to $1: 4$ or more. ${ }^{[4]}$ The ratio was established based on the workload and the services provided to the patients. ${ }^{1}$ The Ministry of Health released the pharmacist workforce required for hospitals. ${ }^{[5,6]}$ Local investigation discussed the demand of hospital pharmacist based on MOH standards. ${ }^{[7,8]}$ However, the pharmacy technician requirement standard for hospital has not existed yet. Also, the ratio of pharmacist to pharmacy technician workforce and demand of the pharmacy techni- cian and forecasting is not ready in Saudi Arabia or Gulf and Middle East countries. The aim of the study was to explore the analysis of pharmacy technician demand over the past twelve years and forecasting in the future within the years 2030 .

\section{METHODS}

It is a retrospective analysis of twelve years (20062017) of Ministry of Health pharmacy technician workforce demand and forecasting in the future (2018-2030) at MOH organization practice. All data were derived from the Ministry of Health Statistical Year Books and any missing appropriate information about pharmacy technician workforce, that will be estimated through allied healthcare professionals data at each region including gender or nationality. ${ }^{[9-20]}$ It included pharmacy technician and exclude all types of pharmacists or clinical pharmacist's workforce at $\mathrm{MOH}$ hospital setting. All types of hospitals or primary health care center levels services 
included in the studies with general, public, pediatrics, maternity, psychiatric hospitals. All specialized centers, cardiac, oncology and dental centers included in the study. All pharmacy technicians expected to provide pharmaceutical according to ASHP definition and requirements. All types of pharmacy services based on the Saudi Central Board of hospital accreditation, Joint Commission on Hospital Accreditation, ASHP best practice standards and general administration of the pharmaceutical care strategic plan. ${ }^{[21-25]}$ All pharmacy technician works at $\mathrm{MOH}$ primary healthcare centers or administration or non-MOH government hospitals and primary care centers excluded from the studies. All private hospital or community pharmacist was excluded from the study. All calculations were based on $\mathrm{MOH}$ workforce standards of hospital with update literatures. ${ }^{[4,8,26]}$ All calculation was done using Microsoft Excel version ten.

\section{RESULTS}

Over 12 past years (2006-2017), the total population of the kingdom of Saudi Arabia was $(23,678,849-32,552,336)$ with an average $(28,283,424.58)$. The Ministry of Health services sixty percent of the pollution and accounted $(14,207,309-19,531,402)$ with an average $(16,970,054.78)$. The number of pharmacists increased $(1,023$ - 3,853) with an average 2,267.08, with (3.76) fold over twelve years and (0.313) increments annually. The number of pharmacy technicians increased $(4,289$ -
$8,373)$ with an average $(6,293.58)$ with (1.9) fold over twelve years and (0.162) increments annually. The number of pharmacy technician demand based on actual pharmacy and pharmacist. The pharmacy technician ratio (1:4) demand was $(197-7,039)$ with an average $(2,774.75)$ annually. While with a ratio of $(1: 2)$ the number of pharmacy technician demand was $(667-2,576)$ with an average $(1,648.25)$ annually. The number of pharmacy technician ratio (1:3) demand was $(98-3,186)$ with an average (507.67) annually (Table 1).

The number of pharmacy technician demand based on optimum pharmacy and pharmacist: The pharmacy technician ratio (1:4) demand was $(21,212.6-26,091)$ with an average $(22,934.68)$ annually. While with a ratio of (1:2) the number of demand pharmacy technician was $(7,410-8,859)$ with an average $(8,320.55)$ annually. The number of pharmacy technician forecasting of ratio (1:3) was (14,300-17,475) with an average $(15,627.62)$ annually (Table 2$)$.

The forecasting number of pharmacy technician in the future within years (2018-2030) over thirteen years based on optimum pharmacy and pharmacist. The pharmacy technician ratio (1:4) forecasting was $(33,898.6$ $45,803)$ with an average $(-39,577.00)$ annually. While with a ratio of $(1: 2)$ the number of the forecasting pharmacy technician was $(16,303$ $22,028)$ with an average $(19,034.31)$ annually. The number of pharmacy technician forecasting of ratio $(1: 3)$ was $(25,100-33,916)$ with an average $(29,305.54)$ annually (Table 3$)$.

\section{DISCUSSION}

The general direction of pharmaceutical care underway pharmacy strategic plan in the mid2000s and restructured plan released in early 2010. The plan contained of development all pharmacy practice services and clinical pharmacy programs with required of pharmacy workforces. ${ }^{[25]}$ There was more one type to calculate the demand for hospital pharmacist. One based on workload analysis with the number of prescriptions. That is each pharmacist can handle $80-120$ prescription per duty with a maximum 150 prescription per day. ${ }^{[27-}$ 29] Another method of pharmacist workforce demand at hospitals with the number of pharmacist per bed..$^{[5,830]}$ The Ministry of Health in the Saudi Arabia stated with 0.2 pharmacists per bed; with $60 \%$ as distributive pharmacists and $40 \%$ clinical pharmacist. ${ }^{[5,30]}$ However, the pharmacy technician workforce demand at hospitals not standardized yet in the healthcare system in the kingdom of Saudi Arabia. The authors calculated the demand through two ways based of the actual number of pharmacist and the optimum number of pharmacist with three ratios of pharmacist to pharmacy technician (1:2), (1:4) and the (1:3) as the average of two previous methods similar to the previous studies. ${ }^{[4,26]}$ The findings showed that is of pharmacy technician demand at the year 2017 reach to almost equal to the present number of a pharmacy technician with the high pharmacist to pharmacy technician ration while reach to $33 \%$ of a presented number. Besides, with using

\begin{tabular}{|c|c|c|c|c|c|c|c|c|c|c|}
\hline 2007 & $24,242,578.00$ & $14,545,546.80$ & 804 & 3,216 & 785 & 1,608 & $-2,393$ & 2,412 & 1,589 & 804 \\
\hline 2008 & $24,807,273.00$ & $14,884,363.80$ & 1,065 & 4,260 & -291 & 2,130 & $-1,839$ & 3,195 & 774 & 1,065 \\
\hline 2009 & $25,373,512.00$ & $15,224,107.20$ & 1,364 & 5,456 & $-1,143$ & 2,728 & $-1,585$ & 4,092 & 221 & 1,364 \\
\hline 2010 & $27,136,977.00$ & $16,282,186.20$ & 1,601 & 6,404 & -704 & 3,202 & $-2,498$ & 4,803 & 897 & 1,601 \\
\hline 2014 & $30,770,375.00$ & $18,462,225.00$ & 2,206 & 8,824 & -476 & 4,412 & $-3,936$ & 6,618 & 1,730 & 2,206 \\
\hline 2015 & $31,521,418.00$ & $18,912,850.80$ & 2,389 & 9,556 & $-1,085$ & 4,778 & $-3,693$ & 7,167 & 1,304 & 2,389 \\
\hline 2016 & $31,742,308.00$ & $19,045,384.80$ & 2,760 & 11,040 & $-2,588$ & 5,520 & $-2,932$ & 8,280 & 172 & 2,760 \\
\hline 2017 & $32,552,336.00$ & $19,531,402.00$ & 3,248 & 12,992 & $-4,619$ & 6,496 & $-1,877$ & 9,744 & $-1,371$ & 3,248 \\
\hline Average & $28,283,424.58$ & $16,970,054.78$ & $1,753.42$ & $7,013.67$ & -720.08 & $3,506.83$ & $-2,786.75$ & $5,260.25$ & $1,033.33$ & $1,753.42$ \\
\hline
\end{tabular}




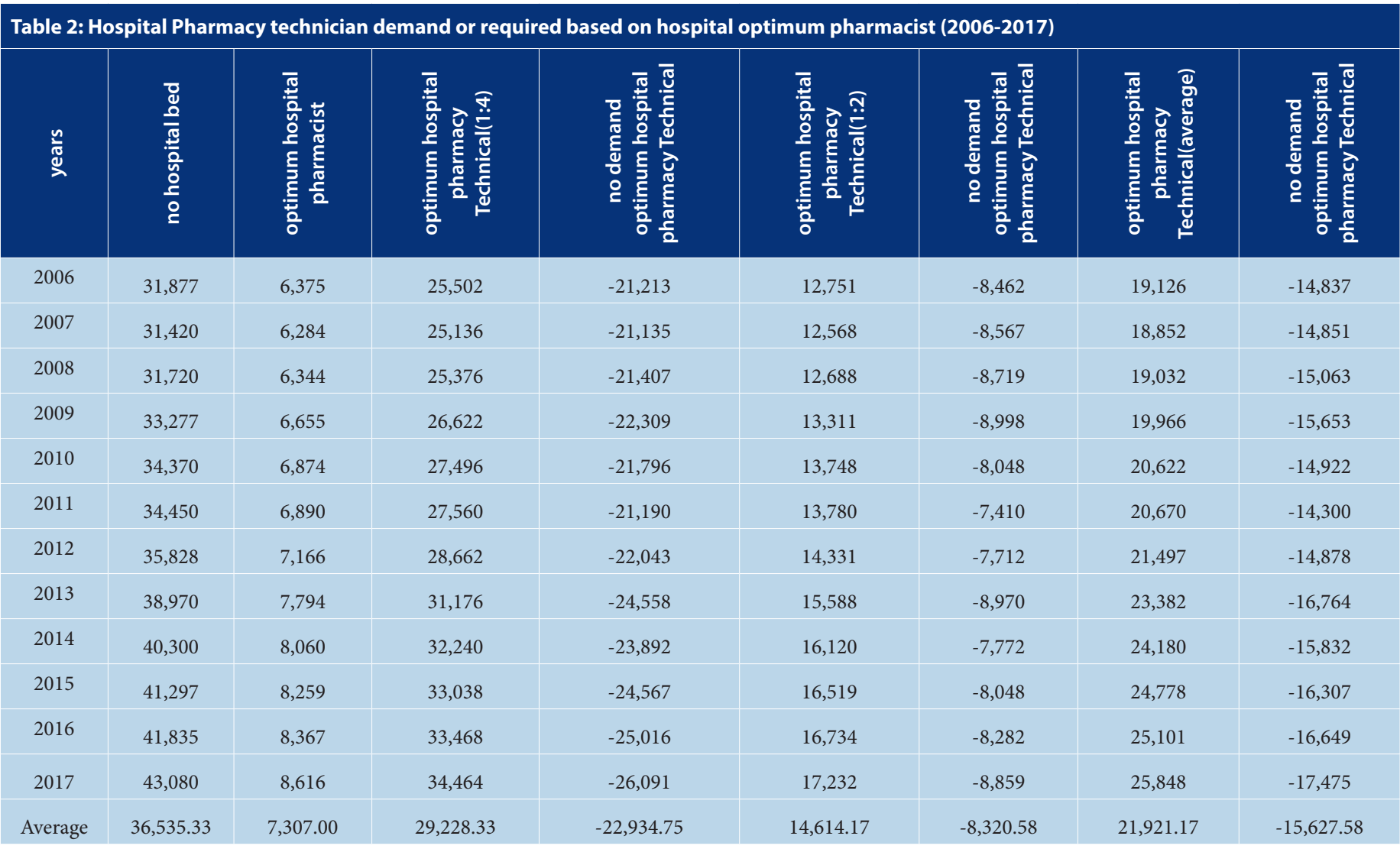

Table 3: Hospital Pharmacy technician forecasting based on hospital optimum pharmacist (2018-2030)

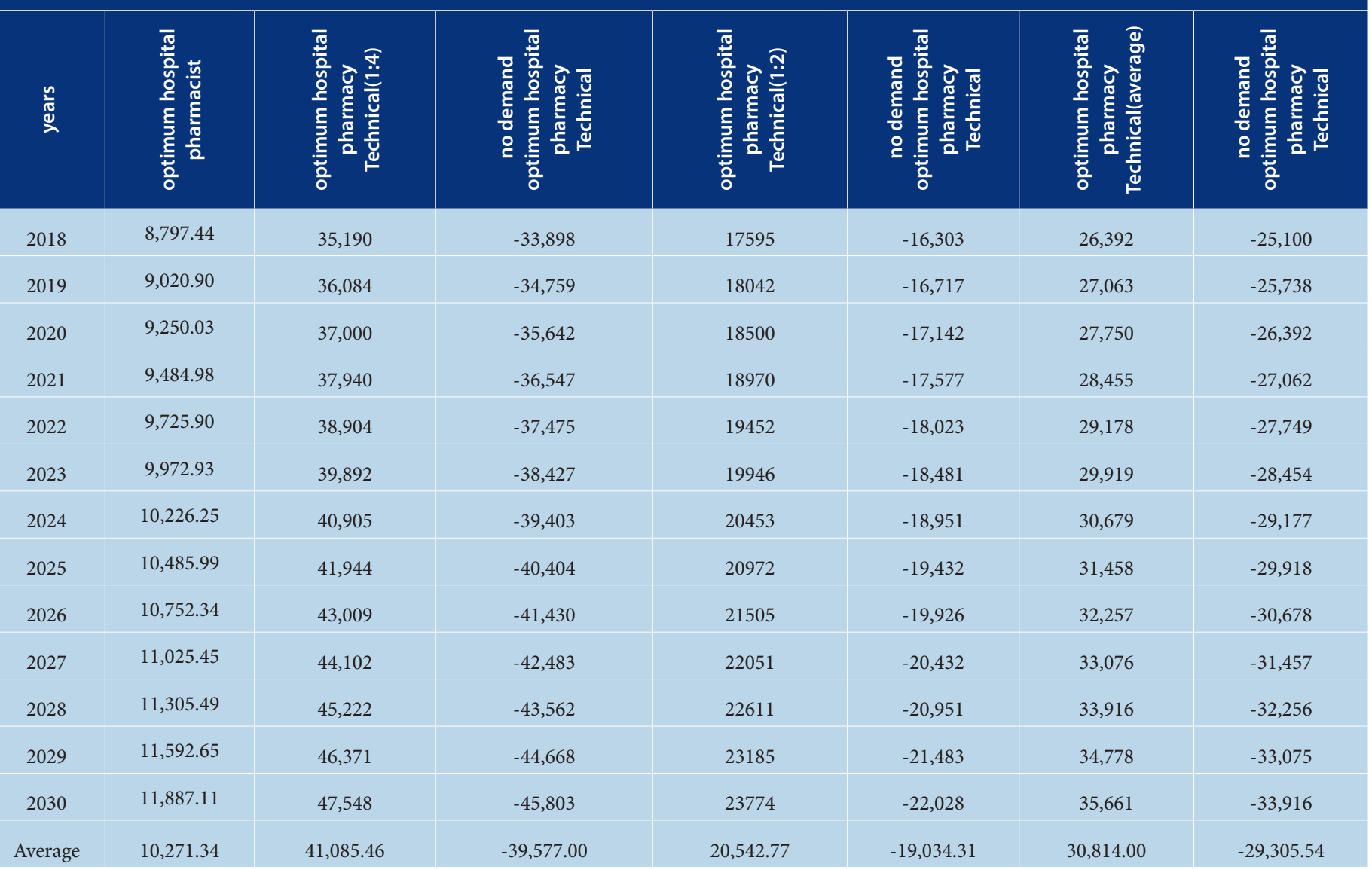


a medium ratio of pharmacy technician ratio, the number of demanded was $38 \%$ of the number of current pharmacy technician numbers. The findings showed the demand of pharmacy technician based on optimum pharmacists was also threefold increments, one-fold increments and two-fold increments with the pharmacist to pharmacy technician ration (1:4), (1:2) and (1:3) respectively. The forecasting demand of pharmacy technician from based on optimum pharmacist 2018 to the 2030 year was almost (4-5) fold increments, (2-2.75) fold increments and (3-2.75) fold increments with the pharmacist to pharmacy ratio (1:4), (1:2) and (1:3) respectively. With the implementation of updated pharmacy strategic plan with new vision 2030 and Saudi managed care pharmacy; most of the pharmacy technician may be converted to community pharmacies after determining the number of the pharmacist at ambulatory care services at hospital sectors. The author suggested the ratio of pharmacy technician (1:1) should convey to the number of a clinical pharmacy technician to help the clinical pharmacist with their daily duties at either hospitals or community pharmacies. The pharmacy technician workforce should report by Ministry of health human resources sectors in such details of nationality, gender, working site and position on an annual basis. The study is first instances in the kingdom of Saudi Arabia and Gulf or Middle East countries and should be repeated with actual data and including all government and private organizations every 2-4 years in the kingdom of Saudi Arabia.

\section{CONCLUSION}

The study of demand and forecasting of pharmacy technician workforce is unique locally and Gulf and Middle East countries. The standardized ratio of pharmacist to pharmacy technician at hospital practice should be determined. The periodically pharmacy technician workforce's demand and forecasting at all healthcare organization is recommended in the Kingdom of Saudi Arabia.

\section{ACKNOWLEDGEMENT}

None.

\section{CONFLICT OF INTEREST}

The authors declare no conflicts of interest.

\section{ABBREVIATIONS}

KSA: Kingdom of Saudi Arabia; MOH: Ministry of Health; ASHP: American Society of
Health-System Pharmacist; PHCs: Primary Healthcare Centers.

\section{ORCID ID}

Yousef Ahmed (D) Alomi https://orcid. org/0000-0003-1381-628X

\section{REFERENCES}

1. Siden R, Tamer HR, Skyles AJ, Dolan CS, Propes DJ, Redic K. Survey to assess the role of pharmacy technicians and nonpharmacist staff in the operation of research pharmacies. Am J Heal Pharm. 2014;71:1877-89.

2. Desselle SP, Holmes ER. Results of the 2015 national certified pharmacy. Am J Heal Pharm. 2017;74(13):981-91.

3. Koehler T, Brown A. A global picture of pharmacy technician and other pharmacy support workforce cadres. Res Soc Adm Pharm. 2017;13(2):271-9.

4. Alkhateeb FM, Shields KM, Broedel-zaugg K, Bryan A, Snell J. Credentialing of pharmacy technicians in the USA. Int $\mathrm{J}$ Pharm Pract. 2011;19(4):219-27.

5. Alomi YA. A new guidelines on hospital pharmacy manpower in Saudi Arabia. J Pharm Pract Community Med. 2016;2(22):30-1.

6. AlomiYA. Primary care center pharmacy manpower new guidelines in Saudi Arabia. J Pharmacol Clin Res. 2016;1(1):1-3.

7. Alomi YA, Alghamdi SJ, Alattyh RA. Primary care centers pharmacist workforce demand in eleven years (2006-2016), and forecasting in fifteen years (2016-2030) at Ministry of Health in Saudi Arabia. J Pharm Pract Community Med. 2018;4(1s):S121S125.

8. Alomi YA, Alghamdi SJ, Alattyh RA. The demand of hospital pharmacist workforce in past eleven years (2006-2016) and forecasting future fifteen years (2016-2030) at all healthcare institutions in Saudi Arabia. J Pharm Pract Community Med. 2018;4(1):97-102

9. Health Statistical Year Book. Saudi Ministry of Health; 2017. Available from: http://www.moh. gov.sa/en/Ministry/Statistics/book/Pages/default. aspx.

10. Health Statistical Year Book. Saudi Ministry of Health; 2016. Available from: http://www.moh. gov.sa/en/Ministry/Statistics/book/Pages/default. aspx.

11. Health Statistical Year Book. Saudi Ministry of Health; 2006. Available from: http://www.moh. gov.sa/en/Ministry/Statistics/book/Pages/default. aspx.

12. Health Statistical Year Book. Saudi Ministry of Health; 2007. Available from: http://www.moh gov.sa/en/Ministry/Statistics/book/Pages/default. aspx.

13. Health Statistical Year Book. Saudi Ministry of Health; 2008. Available from: http://www.moh. gov.sa/en/Ministry/Statistics/book/Pages/default. aspx.

14. Health Statistical Year Book. Saudi Ministry of Health; 2009. Available from: http://www.moh. gov.sa/en/Ministry/Statistics/book/Pages/default. aspx.

15. Health Statistical Year Book. Saudi Ministry of Health; 2010. Available from: http://www.moh. gov.sa/en/Ministry/Statistics/book/Pages/default. aspx.

16. Health Statistical Year Book. Saudi Ministry of Health; 2011. Available from: http://www.moh.
gov.sa/en/Ministry/Statistics/book/Pages/default. aspx.

17. Health Statistical Year Book. Saudi Ministry of Health; 2012. Available from: http://www.moh. gov.sa/en/Ministry/Statistics/book/Pages/default. aspx.

18. Health Statistical Year Book. Saudi Ministry of Health; 2013. Available from: http://www.moh. gov.sa/en/Ministry/Statistics/book/Pages/default. aspx

19. Health Statistical Year Book. Saudi Ministry of Health; 2014. Available from: http://www.moh. gov.sa/en/Ministry/Statistics/book/Pages/default. aspx.

20. Health Statistical Year Book. Saudi Ministry of Health; 2015. Available from: http://www.moh gov.sa/en/Ministry/Statistics/book/Pages/default. aspx.

21. American Society of Hospital Pharmacists. ASHP Statement on Pharmaceutical Care. Am J Hosp Pharm. 1993;50:1720-3

22. American Society of Health-System Pharmacists. ASHP guidelines on a standardized method for pharmaceutical care. Am J Heal Pharm. 1996;53(14):1713-6.

23. Saudi Center Board for Accreditation for Healthcare Institutions (CBAHI). Medication Management (MM). In: National Hospital Standards. 2nd Edition. Saudi Central Board for Accreditation of Healthcare Institutions. 2016, pp.194-211.

24. The Joint Commission. Comprehensive Accreditation Manuals. Joint Commission Resources. 2016. Available from: http://www.jcrinc.com/ store/publications/manuals/.

25. Alomi YA, Alghamdi SJ, Alattyh RA. Strategic plan of general administration of pharmaceutical care at ministry of health in Saudi Arabia 2012 - 2022. J Pharm Pharm Scien. 2015;1(13):1-8

26. Bess DT, Carter J, Deloach L, White CL. Pharmacy technician-to-pharmacist ratios: a state-driven safety and quality decision. J Am Pharm Assoc Pract Pharm Ed. 2014;54(6):648-51.

27. Alomi YA, Alhennawi K, Khayayt N. Pharmacy technician workload and workforce requirements at $\mathrm{MOH}$ hospitals during ten years mass gathering Hajj (2006-2015) in Makah Region, Saudi Arabia. J Pharm Pract Community Med. 2017;3(4s):S107S114

28. Alomi YA, Khayayt N, Alhennawi K,. Pharmacy workload and workforce requirements at $\mathrm{MOH}$ hospitals during ten years mass gathering Hajj (2006-2015) in Makkah Region, Saudi Arabia. J Pharm Pract Community Med. 2017;3(4s): S75S83.

29. Alomi YA, Alhennawi K, Khayayt N. Pharmaceutical care workload and human resources requirements at $\mathrm{MOH}$ hospitals during nine years mass gathering Hajj (2006-2014) in Al-Madina Region, Saudi Arabia. J Pharm Pract Community Med. 2017;3(4s):S61-S66

30. Alomi YA, Alghamdi SJ, Alattyh RA. Forecasting the demand of clinical pharmacist workforce in future fifteen years (2016-2030) at all healthcare institutions in saudi Arabia. J Pharm Pract Community Med. 2018.4(1s):S92-96. 